in men), with a linear increase throughout the study period from 65.3 in 1999 until 70.5 in 2015 ( $p<0.001)$.

The main admission code was for Osteoarticular and connective tissue diseases $(20 \%)$ followed by Circulatory system diseases (16.8\%). There were a total of 18641 intrahospital deaths (5.5\% of all the admissions).

The age-adjusted admission rate was $12.03 / 100$ RA patients* ${ }^{*}$ r (9,12 for women and 1.88 for men). The age-adjusted admission rate increased from 1999 to 2015 (in both genders). An annual increase of admission rate of $3.7 \%$ is estimated. When adjusting by age, the largest increase is observed in patients older than 80 years, with an estimated annual increase of $7.5 \%$.

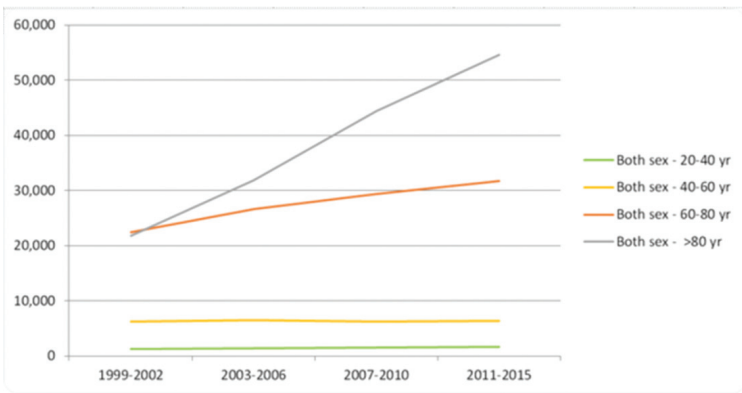

Abstract AB0264 - Figure 1

Conclusions: In Spain, despite the improvement in RA management, there is a global tendency to the increase of admissions during the period of 1999-2015, mainly in $>60$ year, especially in $>80$ year.

Disclosure of Interest: None declared

DOI: 10.1136/annrheumdis-2018-eular.4220

\section{AB0265 CLINICAL PREDICTOR FACTORS ASSOCIATED WITH SUSTAINED DISEASE ACTIVITY AMONG PATIENTS WITH EARLY RHEUMATOID ARTHRITIS}

M.G. Gonzalez Alvarez ${ }^{1}$, J. Molina ${ }^{2}$, L. Nuño ${ }^{2}$, V. Navarro-Compán ${ }^{2}$, A. Villalba ${ }^{2}$ D. Peiteado ${ }^{2}$, P. Bogas ${ }^{2}$, A. Balsa ${ }^{2}$, on behalf of IdiPaz. ${ }^{1}$ Reumatology, $H$. Universitario La Paz, IdiPaz; ${ }^{2}$ Reumatology, Hospital Universitario La Paz, Madrid, Spain

Background: In patients with rheumatoid arthritis (RA), low disease activity (DA) overtime is associated with favourable outcomes. However, the progression of the disease is faster during the first years. Therefore, it is desirable to identify patients with a high probability of sustained DA in an early stage.

Objectives: To identify clinical predictor factors at diagnosis associated with sustained DA after 12 months of follow up in patients with early RA.

Methods: Baseline (at diagnosis) and 12 months follow-up data from an early arthritis clinic was analysed. At both visits, demographic, clinical, laboratory and treatment data were collected and clinical DA was assessed using DAS28 and SDAI. For this study, patients with RA according to physician's diagnosis were selected. Sustained DA at 12 months was defined as DAS28 >3.2 and SDAl>11. Univariate and multivariable logistic regression models were employed to identify which factors are associated with sustained DA.

Results: In total, 566 patients were included. Out of these, $75.8 \%$ were women, $74.7 \%$ Caucasian, $77.7 \%$ RF +and $65.9 \%$ ACPA+. Mean (SD) age was $54^{17}$ years and mean symptoms duration was $16^{15}$ weeks. Regarding treatment, $89.8 \%$ patients received methotrexate as first line treatment and $81.1 \%$ received glucocorticoids. At baseline, $88.8 \%$ had moderate-high DA according to DAS28 $(>3.2)$ and $77.6 \%$ with SDAI (>11). After one year of follow-up, 34\% (DAS28) and $30.9 \%$ (SDAI) remained with moderate-high DA. Univariable logistic regression analysis results are shown in table 1 . Sustained DA was significantly associated with baseline index and its individual components, HAQ, and GCs used for both indexes definitions, with smoking and MTX use for DAS28 definition and RF +for SDAI definition. In the multivariable analysis, sustained DA at 12 months remained significantly associated only with baseline DAS28 (OR 1.34; $p<0.05$ ) for DAS28 definition and with RF (OR 2.6; $p=0.02)$, HAQ (OR 1.06; $p<0.01$ ) and use of glucocorticoids (OR 2.1; $\mathrm{p}<0.05$ ) for SDAI definition.
Abstract AB0265 - Table 1. Univariable logistic regression analysis results

\begin{tabular}{lcccc}
\hline Baseline characteristics & \multicolumn{2}{c}{ DAS28 } & \multicolumn{2}{c}{ SDAI } \\
\hline & OR & $\begin{array}{c}\text { P } \\
\text { value }\end{array}$ & OR & $\begin{array}{c}\text { P } \\
\text { Value }\end{array}$ \\
\hline Age & 1.00 & 0.6 & 0.03 & 1.02 \\
Sex (women) & 1.64 & 0.06 & 0.599 & 1.14 \\
Tabaco & 0.66 & 0.1 & 1.12 & 0.690 \\
Nonsmokers (ref) & 0.58 & 0.05 & 1.08 & 0.804 \\
Past smokers & & & & \\
Smokers & & & & \\
RF (+) & 1.61 & 0.09 & 0.444 & 0.007 \\
ACPA (+) & 0.685 & 0.1 & 0.691 & 0.14 \\
DAS28 & 1.5 & $<0.001$ & & \\
SDAl & & & 1.00 & 0.008 \\
HAQ & 1.05 & 0.001 & 1.07 & $<0.001$ \\
ESR & 1.01 & 0.001 & 1.01 & $<0.001$ \\
PCR & 1 & 0.804 & 1.0 & 0.91 \\
Pain & 1.02 & $<0.001$ & 1.01 & $<0.001$ \\
Patients Global Assessment & 1.01 & $<0.01$ & 1.01 & 0.002 \\
Evaluator Global & 1.02 & $<0.001$ & 1.02 & $<0.001$ \\
Assessment & & & & \\
Swollen Joint count 28 & 1.07 & $<0.001$ & 1.07 & $<0.001$ \\
Tender Joint Count 28 & 1.07 & $<0.01$ & 1.06 & $<0.001$ \\
Methotrexate use & 8,2 & $<0.05$ & 2,4 & 0,2 \\
Glucocortoids use & 1.8 & $<0,05$ & 2,7 & $<0.001$ \\
\hline
\end{tabular}

Conclusions: One out of three patients with RA maintains DA 12 months after diagnosis. The predictors for this status depend on the index employed: DAS28 at baseline is the best predictor for sustained disease activity when using DAS28definition. Conversely, positive RF, impaired functionality and the need of glucocorticoids at baseline are associated with the SDAI-definition.

Disclosure of Interest: None declared

DOI: 10.1136/annrheumdis-2018-eular.3543

\section{AB0266 ESTIMATION OF CEREBROVASCULAR REACTIVITY IN PATIENTS WITH RHEUMATOID ARTHRITIS}

M. Salokhiddinov, U. Anarmetova, G. Haydarova. Tashkent Medica Academy, Tashkent, Uzbekistan

Background: Rheumatoid arthritis (RA) is a chronic autoimmune disease with high cardiovascular risk. Arterial hypertension $(\mathrm{AH})$ is the most common comorbid condition in RA and one of the main risk factors for stroke. Chronic immune inflammation, characteristic of RA, also has a damaging effect on the vascular wall and can lead to a marked decrease in the compensatory possibilities of the cardiovascular system. It has been shown that the violation of cerebrovascular reactivity (CVR) significantly increases the risk of developing acute cerebral ischemia Objectives: The goal is to study the condition of the CVR in RA patients, depending on the level of blood pressure (BP)

Methods: the study involved 70 patients with RA at the age of $59,2 \pm 7,3$ years with the duration of RA $13 \pm 8,9$ years were examined. The DAS28 index was 3.87 \pm 1 .33. Depending on the level of blood pressure, two groups were isolated: group $1(n=56)$ - patients with hypertension and group $2(n=14)$ - with normal blood pressure. CVR was assessed by means of transcranial dopplerography of middle cerebral arteries (MCA) using hyperoxic (inhalation of $100 \%$ oxygen, phase of vasoconstriction) and hypercapnic (inhalation of $4 \%$ of a mixture of carbon dioxide with air, phase of vasodilation) of samples

Results: The result showed that $15(27 \%)$ patients of the I group and $3(21 \%)-$ the II group had an adequate decrease in the linear velocities of the blood flow (LVBF) in the MCA. An insufficient reduction in hypervascular hypertension was found in 28 \% $\%$ and $8(57 \%)$ patients, a paradoxical increase in the LVBF(perverse reaction) in $12(21,4 \%)$ and $4(28,5 \%)$ patients, respectively. In a hypercapnia trial, only about a third of patients registered an adequate increase in LBVF for hypercapnia. A decrease in the response occurred in $27(48 \%)$ and $9(61 \%)$ patients, excessive increase in LVBF (hyperergic reaction) - in $15(26 \%)$ and 2 (14\%) patients, respectively

Conclusions: There was a violation of the CVR on metabolic (hyperoxic and hypercapnic) stimuli based on the results of transcranial dopplerography of most RA patients, regardless of the level of blood pressure

\section{REFERENCES:}

[1] Machold KP, Stamm TA, Eberl GJM, et al. Very recent onset arthritis: Clinical, laboratory, and radiological findings during the first year of disease. Journal of Rheumatology 2002;29(11):2278-2287.

[2] Arndt U, Behrens F, Ziswiler HR, et al. Observational study of a patient and doctor directed pre-referral questionnaire for an early arthritis clinic. Rheumatology International 2007;28(1):21-26. 
Disclosure of Interest: None declared

DOI: 10.1136/annrheumdis-2018-eular.2154

\section{AB0267 BASELINE PREDICTORS OF RESPONSE TO METHOTREXATE IN EARLY RHEUMATOID ARTHRITIS}

S. Rizvi, M. Bukhari. Rheumatology, Royal Lancaster Infirmary, Lancaster, UK

Background: The disease activity score (DAS28) is widely used to assess response to treatment in early rheumatoid arthritis. Few studies have looked at the individual components of the DAS at baseline to predict drop in DAS28 in early disease. Specifically at 3, 6 and 12 months. Predicting response early in disase would enable more targetted treatments to be given and patients selecteed early for more aggressive disease control. Although certain biomarkers have been advocated for use and have shown some promise. ${ }^{1,2}$ there is still a place for exploring using more clinically derived indicators.

Objectives: To determine whether DAS28 response at 3,6 and 12 months could be predicted by baseline components of the DAS28

Methods: The study used patients from the multicentre UK based RAMS study. All patients with early rheumatoid arthritis starting methotrexate were enrolled. We used data from a single centre in the North west of England for the analysis. DAS28 and it's components were recorded at baseline and at 36 and 12 months. Baseline components of the DAS28 were used to predict the change in DAS from baseline to 36 and 12 months. Linear regression was used with subsequent adjustment for age and gender.

Results: 120 patients were enrolled in the study, median age was 62.4 years (IQR42.1, 72.5), 81 (67\%) were female. Median das28 at baseline was 5.3 (IQR $4.2,6.2$ ). Duration of symptoms was 9 months (IQR 2,11). There was a drop of DAS28 of 1.49 at 3 months (IQR $0.57,2.45$ ) and at 6 and 12 months it was 1.84 (IQR $0.48,2.91$ ) and 1.63 (IQR $0.72,2.85$ ) respectively. At three months the only baseline predictor of change in DAS28 was the patient global assessment unadjusted and adjusted for age adjusted beta $0.01295 \% \mathrm{Cl} 0.002,0.023(\mathrm{p}=0.02)$. At six months the baseline tender joint count adjusted beta $0.0895 \% \mathrm{Cl} 0.015$, $0.154(\mathrm{p}=0.01)$ as well as swollen joint count adjusted beta $0.0595 \% \mathrm{Cl}$ $0.004,0.095(p=0.02)$ also predicted reposnse in addition to the patients global assessment adjusted beta $0.01695 \% \mathrm{Cl} 0.002,0.03(\mathrm{p}=0.01)$, but not the ESR or CRP at baseline $(p=N S)$. At 12 months the only predictors of response was the baseline CRP adjusted beta $0.0295 \% \mathrm{Cl} 0.005,0.04(\mathrm{p}=0.02)$.

Conclusions: In this cohort of patients with early disease, response to methotrexate could not be reliably predicted using baseline measures and the ability to predcit patients who would improve could not be found in this cohort. Further work on other clinical biomarkers to predict response is needed.

\section{REFERENCES:}

[1] Arthritis Res Ther. 2016 Feb 1;18:37.

[2] Rheumatology (Oxford). 2017 Jun 1;56(6):973-980.

Disclosure of Interest: None declared

DOI: 10.1136/annrheumdis-2018-eular.5538

\section{AB0268 HOW DO PATIENTS WITH RHEUMATOID ARTHRITIS EVALUATE THEIR GLOBAL ASSESSMENT?}

M. Kojima ${ }^{1}$, T. Kojima ${ }^{2}$. ${ }^{1}$ Medical Education, Nagoya City University Graduate School of Medical Sciences; ${ }^{2}$ Orthopedic Surgery, Nagoya University Hospital, Nagoya, Japan

Background: The importance of patient-reported outcomes (PRO) has been recently recognised. Patient global assessment (PtGA) is one of the most popular PROs in rheumatology. However, the validity of PtGA as a tool for assessment of disease activity and its relevance compared with other tools is still debated. ${ }^{1}$ Patients' perspective is essential to achieve treat-to-target. The significance of measuring PtGA in clinical practice should be verified. We previously found that Japanese rheumatologists changed their strategy to ask patient global assessment (PtGA) according to the patients' understanding ability. It is unknown how patients themselves feel PtGA.

Objectives: To investigate how patients with rheumatoid arthritis (RA) evaluate and accept PtGA as assessment tool of RA activity.

Methods: During the period of , August and September, 2016 a 90 min focus group was held four times. Nine or 10 RA patients participated in each focus group. Totally, 34 women and 4 men, average age $56.1 \pm 10.9$ years old, and disease history 9.39 \pm 9 . 36 years joined the study. The participants freely discussed how to evaluate their conditions of rheumatism and therapeutic effect. We used the "Steps for Coding and Theorization" (SCAT) ${ }^{2-3}$ to analyse the focus group data.

Results: Patients determined their PtGA based on pain, swelling, inconvenience of daily life, the mood of the day, comprehensively, although they felt confusing because the criteria of how to evaluate PtGA was unclear. Most patients set 100 of PtGA as "when most painful after onset", while standard of 0 was varied. Many patients had experienced a discrepancy between PtGA and CRP that their doctors denied. Patients were eager that their doctor would understand the discordance between PtGA and laboratory data and ask the patients "what's wrong with you?"

Conclusions: Doctors and patients should discuss how to evaluate PtGA at the start of treatment to avoid patients' confusing. By utilising PtGA as a communication tool, relationship between doctor and patients would be facilitated.

\section{REFERENCES :}

[1] Kojima M, Kojima T, Suzuki S, Takahashi N, Funahashi K, Asai S, Yoshioka Y, Terabe K, Asai N, Takemoto T, Ishiguro N. Patient-reported outcomes as assessment tools and predictors of long-term prognosis: a 7year follow-up study of patients with rheumatoid arthritis. Int J Rheum Dis. 2017;20(9):1193-1200.

[2] Otani T. "SCAT" A qualitative data analysis method by four-setp coding: Easy startable and small scale data-applicable process of theorization. Bulletin of the Graduate School of Education and Human Development (Educational Sciences), Nagoya University 2007;54:27-44.

[3] Kojima M, Nakayama T, Otani T, Hasegawa M, Kawahito Y, Kaneko Y, Kishimoto M, Hirata S, Seto Y, Endo H, Ito H, Kojima T, Nishida K, Matsushita I, Tsutani K, Igarashi A, Kamatani N, Miyasaka N, Yamanaka H. Integrating patients' perceptions into clinical practice guidelines for the management of rheumatoid arthritis in Japan. Mod Rheumatol. 2017;27 (6):924-929.

Disclosure of Interest: None declared

DOI: 10.1136/annrheumdis-2018-eular.2662

\section{\begin{tabular}{|l|l}
\hline AB0269 ANKLE SYNOVITIS AND TREAT-TO-TARGET STRATEGY \\
\hline
\end{tabular} IN CLINICALLY AND SEROLOGICALLY DIFFERENT FORMS OF RHEUMATOID ARTHRITIS, A SINGLE- CENTRE EXPERIENCE}

M. Kedves $^{1}$, J. Gál ${ }^{1}$, K. Törőcsik ${ }^{1}$, D. Balaton ${ }^{1}$, J. Csitos ${ }^{1}$, N. Megyes ${ }^{1}$, G. Nagy ${ }^{2}$. ${ }^{1}$ Rheumatology, Bacs-Kiskun County Hospital, Kecskemét; ${ }^{2}$ Rheumatology, Semmelweis University, Budapest, Hungary

Background: DAS28 based treat-to-target (T2T) strategy ${ }^{1}$ was shown to improve outcomes in patients with rheumatoid arthritis (RA). Although previous studies have shown that approximately $1 / 3$ of RA patients have foot symptoms $\left[{ }^{2}\right.$ ankle and foot joints are not included in DAS28.

Objectives: To study the prevalence of ankle synovitis in clinically and serologically different forms of RA, treated according to the updated T2T strategy.

Methods: 1109 patients, with RA, treated according to the T2T approach were included in this study. Concurrent tenderness and swelling of the ankle joint were considered as synovitis. Rheumatoid factor (RF) and anti-mutated citrullinated vimentin (anti-MCV) positive and negative patients with different disease activity were evaluated

Results: $8.47 \%$ (94) patients had high (DAS28 >5.1); 35.25\% (391) moderate (DAS28 $\leq 5.1 ;>3.2$ ) and $18.66 \%$ (207) low (DAS28 $\leq 3.2 ; \geq 2.6$ ) disease activity. $37,6 \%(417)$ of patients were in clinical remission (DAS28 $<2.6$ ). $60.71 \%{ }^{17}$ of antiMCV and RF positive and $44.8 \%{ }^{13}$ of anti-MCV and RF negative patients with high disease activity had ankle synovitis (table 1). Regarding patients in remis sion, $13.7 \%{ }^{18}$ of anti-MCV and RF positive and $15 \%{ }^{18}$ of anti-MCV and RF negative patients had ankle synovitis (table 2). Interestingly, ankle synovitis was considerably more common than knee synovitis in all patient groups.

Abstract AB0269 - Table 1. Ankle and knee involvement in high disease activity

\begin{tabular}{lccc}
\hline & $\begin{array}{c}\text { DAS28 }>5,1 . \\
94 \text { patients } \\
\text { in total }\end{array}$ & $\begin{array}{c}\text { DAS28>5,1. RF pos., } \\
\text { anti-MCV pos: } \\
28 \text { patients }\end{array}$ & $\begin{array}{c}\text { DAS28>5,1. RF neg, } \\
\text { anti-MCV neg: } \\
29 \text { patients }\end{array}$ \\
\hline Right knee synovitis & $21,27 \%$ & $25 \%$ & $24,13 \%$ \\
Left knee synovitis & $19,14 \%$ & $25 \%$ & $10,31 \%$ \\
Both knees synovitis & $4,25 \%$ & $10,71 \%$ & 0 \\
$\%$ of patients with knee & $36,17 \%$ & $39,28 \%$ & $34,48 \%$ \\
involvement & & & \\
Right ankle synovitis & $31,91 \%$ & $28,57 \%$ & $34,48 \%$ \\
Left ankle synovitis & $37,23 \%$ & $42,85 \%$ & $44,82 \%$ \\
Both ankles synovitis & $13,82 \%$ & $10,71 \%$ & $34,48 \%$ \\
$\%$ of patients with ankle & $55,31 \%$ & $60,71 \%$ & $44,82 \%$ \\
involvement & & &
\end{tabular}

